\title{
O PARADOXO DAS TECNOLOGIAS DE SAÚDE: DA RACIONALIDADE PARAMÉTRICA À RACIONALIDADE ESTRATÉGICA
}

\author{
Conceição Assis Pacheco ${ }^{1}$ \\ Albino Lopes ${ }^{2}$
}

\begin{abstract}
Resumo: Este estudo teve como objectivo a construção de um instrumento de medição do estado de desenvolvimento profissional dos profissionais das tecnologias da saúde (PTS) que possibilite conhecer da forma como as Organizações dos Serviços de Saúde (OSS) poderiam, adequadamente, integrar os PTS na rede de prestação de cuidados. Funda-se a investigação na constatação de que a racionalidade que enforma a GRH destes activos em Saúde obsta à sua plena integração no Sistema e impede o desenvolvimento dos capitais detidos quando os PTS são ponto nodal no Sistema de Saúde já que intervêm em todas as fases de um processo de doença, ou de saúde e são responsáveis por uma fatia considerável dos gastos em saúde. O texto discute a relevância desta evidência num contexto de escassez de estudos empíricos sobre a temática das Profissões das Tecnologias da Saúde (TS). A estruturação do instrumento teve por base dois painéis de peritos que integravam gestores, professores das TS, sindicalistas e PTS com responsabilidades de gestão, através de uma metodologia de Painel de Delphi. O instrumento construído
\end{abstract}

1 conceicao.assispacheco@gmail.com; Doutoranda em Ciências Sociais na Área do Comportamento Organizacional no Instituto Superior de Ciências Sociais e Politicas; Mestre em Gestão de Recursos Humanos pelo Instituto Superior de Ciências do Trabalho e da Empresa; Técnica de Diagnóstico e Terapêutica Principal de Análises Clínicas do Hospital Ortopédico de Sant'Ana, Santa Casa da Misericórdia de Lisboa, Parede, Portugal

2 alopes@iscsp.utl.pt; Doutor em Psicologia, na área da Psicologia Social e das Organizações, pela Faculdade de Psicologia e Ciências da Educação da Universidade Católica de Louvain (Bélgica); Doutor em Organização e Gestão de Empresas, na especialidade de Recursos Humanos e Comportamento Organizacional, pelo Instituto Superior de Ciências do Trabalho e da Empresa; Professor Catedrático e Coordenador da Unidade de Gestão no Instituto Superior de Ciências Sociais e Políticas 
facilitará a tomada de uma base mais científica para a empiria e a casuística que fundam o pensamento sobre estas profissões. As conclusões da sua aplicação fundamentarão práticas de GRH mais adequadas.

Palavras-chave: Cuidados de Saúde; Profissões e Ocupações; Mudanças Tecnológicas: escolhas e consequências.

Classificação do JEL: I11 - Mercados de Cuidados de Saúde; J44 - Mercados de Trabalho Profissional e Ocupações; O33 - Mudanças Tecnológicas: Escolhas e Consequências.

\begin{abstract}
The present study aims to develop an instrument to measure the professional development stages of health care technologies professionals (HCTP), which will allow to understand the way health care organizations (HCO) could adequately incorporate the HCTP into the health care network.

The research is based on evidence showing that the kind of rationality underlying the HRM of those assets on the health care domain hinders from its complete integration within the system, and prevents the development of owned capitals whenever HCTP have a pivotal role in the health care system. The case is due to the fact of intervening in all phases of the disease or health process, and being responsible for a substantial part of overall health care costs.

The article discusses the relevance of this evidence within a context of scant empirical studies on the subject of health care technologies (HCT) professions. The instrument design was based on two panels of experts made up of managers, HCT professors, union representatives, and HCTP having managerial responsibilities, using a Delphi methodology.

The instrument herein developed will make it more feasible to expand the scientific basis for the empiricism and causality backing up the current thinking about these professions. Future conclusions to arise from its use will set up more adequate and effective HRM practices.
\end{abstract}

Key Words: Health Care; Professions and Occupations; Technological Changes: Choices and Consequences.

JEL Classification: I1 1 - Health Care Markets; J44 - Professional Labour Markets and Occupations; O33 - Technological Changes: Choices and Consequences.

\title{
INTRODUÇÃO
}

O trabalho em Gestão consiste em compreender e integrar tensões e paradoxos mais do que em simplificar realidades complexas (Rego \& 
Cunha, 2007), fazendo uma abordagem à realidade organizacional capaz de reconhecer, descodificar e propor soluções para resolver provisoriamente esses mesmos estados contraditórios e paradoxais que caracterizam as comunidades humanas.

A área da saúde é, hoje, indiscutivelmente um terreno de variadas dimensões, múltiplas nuances e infindáveis quadrantes que requer a contribuição de uma multiplicidade de áreas de saber (Santana \& Costa, 2008; Pais Ribeiro \& Leal, 2011).

A questão de partida para este trabalho é a de procurar conhecer o que reserva o futuro às profissões das Tecnologias da Saúde (TS), através de uma exploração da realidade, e sabendo que a evolução dos saberes que as suportam tem relação directa com as descobertas em áreas científicas que vão da química ao tratamento de imagem, da informática à biologia, da matemática à genética, da física à psicologia, da sociologia às engenharias de sistemas e à electrotecnia, das ciências biomédicas às normas legais, numa constante interação e em permanente mudança.

De entre as várias funcionalidades indispensáveis aos cuidados de saúde está o conjunto de saberes e metodologias de aproximação ao corpo (Serra, 2006) que compõem as Tecnologias da Saúde. Estas constituem uma área de actividade fundamental para o estabelecimento de um diagnóstico clínico correcto, para o prognóstico e avaliação da evolução da patologia, para a reabilitação pessoal e humana e para a reinserção social e profissional do paciente. A montante, têm em vista a avaliação do estado de saúde e a implementação de adequadas medidas de prevenção de doença e promoção da saúde.

Por conseguinte, o trabalho em saúde desenvolve-se pontuado pelo constante recurso às tecnologias de diagnóstico e às terapêuticas, isto é, aos saberes teóricos e práticos que os Profissionais das Tecnologias da Saúde (PTS) detêm pela sua específica qualificação. Estes profissionais são, assim, um ponto nodal no Sistema de Saúde (SS) já que intervêm em todas as fases de um processo de doença e são responsáveis por uma fatia considerável dos gastos em saúde.

\section{OBJETIVOS DO ESTUDO}

A questão de partida é a de que, com o desenvolvimento dos sistemas de saúde estes profissionais, de auxiliares do médico, passaram a complemento e, daí, a fundamento da ação clínica, e, hoje, assumem-se 
como ponto nodal do sistema de saúde. Esta evolução sucede da história das profissões, da mudança incutida pelas inovações constantemente introduzidas nos cuidados de saúde e da realidade vivida nas organizações.

Constatada a escassez de investigação sobre o capital de conhecimento detido e os potenciais de desenvolvimento ínsitos neste grupo de profissionais da saúde, e na circunstância de decorrer sucessivamente adiada por falta de soluções plausíveis - uma negociação com as instâncias governamentais para a revisão da regulação das profissões, reenquadramento profissional e legal no serviço público de saúde (e por arrastamento no sector privado) realiza-se a marcada atualidade e pertinência deste estudo.

O objetivo geral deste estudo é, então, o de discutir o desenvolvimento de um instrumento que permita revelar a realidade sobre as profissões das TS, em termos de desenvolvimento profissional e fronteiras de atividades. Pretende-se, igualmente, descrever a atual posição deste grupo profissional nas OSS, nomeadamente: conhecer o seu estado de consolidação e desenvolvimento; compreender que reflexos têm nas práticas de gestão a emergência de profissionais altamente qualificados nas atividades de diagnóstico e de terapêutica; e, debater futuros possíveis inferindo sobre a forma como a GRH nas OSS deveria evoluir para, adequadamente, integrar os profissionais das tecnologias da saúde na rede de prestação de cuidados de saúde.

\section{ENQUADRAMENTO TEÓRICO DO TEMA}

\subsection{Revisão da Literatura}

A revisão da literatura incidiu, sobretudo sobre os conceitos de integração e diferenciação (Santana \& Costa, 2008), sobre as racionalidades (Carapinheiro, 2006, Pita Barros \& Simões, 2007) e os paradigmas que iluminam a GRH (Proença, Morais Vaz, Escoval, Candoso, et al, 2000, Reis, 2007, Carvalho, 2008), e sobre as teorias que os académicos já antecipam, mas que a prática ainda não adoptou (Lopes \& Barrosa, 2008), sempre com orientação para o sistema (ACS, 2009) e a gestão da saúde (Carvalho Rodrigues, Ginó, Sena \& Dahlin, 2002, MS, 2010) e, naturalmente, com foco constante naqueles que elegem os PTS como matéria de estudo (Tavares, 2007). Também foram tidas em conta as normas jurídicas que regulam estas profissões e os projectos de revisão 
do seu enquadramento socioprofissional e organizacional. (Cardim \& Miranda, 2007, Correia de Campos, 2008, Dussault \& Dubois, 2003, Martin et al, 2009, Stoleroff \& Correia, 2008).

Da extensa revisão da literatura levada a cabo, foi possível verificar a imensa escassez de trabalhos que tomam para seu objecto de análise os grupos profissionais das áreas relacionadas com as tecnologias de diagnóstico e terapêutica, quer se busque na literatura sociológica, quer na literatura de gestão de recursos humanos, em revistas portuguesas ou em livros e manuais.

Designadamente, não foram encontrados trabalhos que tenham escolhido como seu objectivo a análise das condições de exercício profissional nestas áreas de actividade, das formas como estes Recursos Humanos (RH) são enquadrados nas Organizações dos Serviços de Saúde (OSS) onde exercem as suas profissões, ou da adequação das práticas que enformam a sua gestão.

Como era expectável também não se detectou qualquer menção a esta matéria em revistas internacionais uma vez que a regulamentação e organização destas profissões são específicas de cada País e directamente dependentes de orientações políticas e macroeconómicas e de práticas sociais.

Sobre as dinâmicas de profissionalização, as quais são especificamente portuguesas, existem alguns estudos, essencialmente endógenos, preocupados com a história (Lobato, 2001, Freitas, 2007, Coutinho, Silveira Sérgio, Paiva de Sá \& Salgueiro, 2010), a formação (Conde, 2006) e a evolução das profissões (Tavares, Lobato, Medeiros et al., 2002, ESTeSL, 2007), em matéria de saberes (Estevão, 2006), competências (Vital, Baltazar, Gavinho \& Mendes, 2006) e atitudes (Coutinho, 2003). Também os há mais sociológicos (Tavares, 2002; Lopes, 2006; Tavares, 2007), ou mais políticos (Lopes, 2004; Lourtie \& Pinto, 2007).

Outros, ainda, tocam a problemática muito marginalmente, e apenas como constatação das relações que se estabelecem no seio de equipas de trabalho referenciadas ao trabalho médico, de que é exemplo o de Areosa \& Carapinheiro (2008).

Documentos oficiais que se consultem, tais como o Healthforall.database da OMS, mencionam os grupos profissionais de medicina e enfermagem (OPSS, 2009), e muito raramente os PTS. Quando o fazem, é para os enquadrar no nível organizacional de menores 
qualificações, assistentes administrativos e mesmo auxiliares (MS, 2010). Desta forma se comprova a mudez desta componente da estrutura (Lopes, 2011) dos SS, a premência do estudo deste grupo profissional e a actualidade e pertinência do presente trabalho.

Aliás, a análise que de seguida se faz da realidade organizacional mais, firmemente, atesta o afirmado.

\subsection{Profissões e Profissionais das Tecnologias da Saúde}

De forma inovadora, e modelar em termos europeus e mesmo mundiais, desde $1977^{3}$ que, no nosso País, as profissões das Tecnologias da Saúde estão integradas num grupo que se organiza, fundado nas áreas de prestação de cuidados em saúde: medicina, enfermagem, meios complementares de diagnóstico e terapêutica ou, sendo o mesmo, actividades paramédicas, com o apoio de assistentes operacionais e de assistentes administrativos.

Hoje, e por força de normativos reguladores publicados ainda na década de noventa do século passado e com a obsoleta designação de Técnicos de Diagnóstico e Terapêutica ${ }^{4}$, o grupo de profissões das Tecnologias da Saúde "no seu conceito tradicional" (Conde, 2006) inclui os cursos e as 18 (dezoito) profissões aqui nomeadas por ordem alfabética: Análises Clínicas e Saúde Pública; Anatomia Patológica, Citológica e Tanatológica; Audiologia; Cardiopneumologia; Dietética; Farmácia; Fisioterapia; Higiene Oral; Medicina Nuclear; Neurofisiologia; Ortoprotesia; Ortóptica; Prótese Dentária; Radiologia; Radioterapia; Saúde Ambiental; Terapia da Fala; Terapia Ocupacional.

Com o desenvolvimento dos sistemas de saúde estes profissionais compõem hoje um conjunto de profissões regulamentadas pelo Estado, quer nas competências a adquirir em formação exigida para o exercício, quer nas condições em que o exercício profissional se realiza.

O conceito de tecnologias da saúde relaciona um conjunto de profissões com um percurso de largos anos em comum, e algumas delas,

\footnotetext{
${ }^{3}$ Decreto Regulamentar 87/77, de 30-12 que cria a carreira de Técnico Auxiliar dos Serviços Complementares de Diagnóstico e Terapêutica nela englobando 13 profissões pela primeira vez sendo assumida a constituição em grupo pelo paralelismo da posição nas atividades em saúde.

${ }^{4}$ Decreto-Lei n ${ }^{\circ} 564 / 99$, de 24-12, mas a designação remonta a 1985 com o DecretoLei $\mathrm{n}^{\circ} 384-\mathrm{B} / 85$, de 30-9

${ }^{5}$ Sobre esta matéria ver Lopes, N. 2006.
} 
com muitos anos de história. Desde $1980^{6}$ que as 18 profissões têm mantido um percurso absolutamente comum aquando da definição de políticas governamentais, tendo percorrido os mesmos passos quer no ensino, quer no exercício. Vêm-lhes sendo aplicadas as mesmas regras em todos os campos de acção desde o acesso aos cursos e ao exercício profissional, aos planos de estudo, às carreiras e às convenções colectivas de trabalho (Conde, 2006).

Contudo, todas se diferenciam pelos saberes que devem deter, pelas metodologias e técnicas que dominam e pelas tecnologias específicas que utilizam.

Os seus saberes fundacionais vão da mecânica e biomecânica à anatomia humana, passando pela biologia molecular e celular, a óptica, a fonologia, a neurociência, a hemodinâmica, a química biológica, a microbiologia, a genética, a farmacologia, a biofísica e a física, o controle de radiações e radionuclidos, o conhecimento dietético e nutricional, as ciências do ambiente, a matemática, especificamente, a bioestatística, a eletrónica e, hoje, também a informática avançada, sem esquecer os saberes transversais como a fisiologia e a patologia ou a psicologia e a sociologia ou, ainda, a deontologia profissional e a bioética.

Muitos destes saberes são transversais a várias profissões, como, por exemplo, a química biológica ou a biologia molecular que são saberes fundamentais em análises clínicas, anatomia patológica e farmácia, tal como a física é comum às três profissões radiológicas - imagiologia, radioterapia e medicina nuclear - ou a biomecânica que é comum à fisioterapia, à terapia ocupacional e à ortoprotesia, a neurociência que é comum à terapia da fala, à fisioterapia e à neurofisiologia, a anatomia que é basilar para as profissões radiológicas, a fisioterapia e a ortoprotesia ou mesmo a fonologia que é base da terapia da fala e da audiologia, de entre outros exemplos possíveis.

As metodologias também são diversas e estabelecem agrupamentos de actividade distintos dos anteriores. Assim, e apontando apenas exemplos, os métodos registográficos são preponderantes nas profissões de neurofisiologia, cardiopneumologia e audiologia enquanto as metodologias de imunoquímica, citologia ou biologia molecular são

\footnotetext{
${ }^{6}$ Com a criação das Escolas através da Portaria $n^{\circ} 709 / 80$, de 23-9 e a carreira já instituída pelo DReg 87/77.
} 
comuns às profissões laboratoriais - análises clínicas e anatomia patológica, citológica e tanatológica.

Podemos considerar as questões enquadradoras do problema das profissões das tecnologias da saúde segundo três dimensões: uma dimensão histórica que divisa as circunstâncias que condicionam a actual conjuntura; uma dimensão social que abarca as relações e as fronteiras com outros actores presentes no campo; e uma dimensão política que decide os futuros.

\subsection{Dimensão Histórica}

As profissões das Tecnologias da Saúde (TS) são relativamente recentes nas organizações de saúde, apesar de alguns saberes, e práticas, que lhes são próprias terem raízes milenares, como as que se aplicam em fisioterapia ou nas actividades do medicamento.

Nos últimos trinta anos e por força da abrangente, imensa e crescente diversidade de saberes que os PTS devem deter para um exercício capacitado e capaz, a sua formação foi sucessivamente aprofundada, alargada e prolongada.

Hoje, é-lhes exigida uma formação de nível 5 pelo ISCED (Internacional Standard Classification for Education), diploma de licenciatura de quatro anos de duração e 240 ECTS, segundo os critérios do Processo de Bolonha.

O exercício, pela diversidade crescente das necessidades dos clientes internos ao próprio sistema de saúde, os outros profissionais cuja actividade depende dos resultados da produção destes como os médicos e os enfermeiros; e externos, as pessoas, doentes ou sãs - exigem especializações várias de que as instituições de ensino também já reconheceram a necessidade e oferecem na forma de pós-graduações e Mestrados. Muitos profissionais vêm regressando à Escolas para as frequentar, cientes de que a formação nestas áreas é uma constante da vida.

\subsection{Dimensão social}

Com o progresso exponencial das tecnologias e a diversificação das necessidades este grupo de profissões é um ponto de charneira nos cuidados de saúde pois que, do seu labor, saberes e competências próprias, depende, hoje, qualquer diagnóstico, prognóstico clínico, 
terapêutica, reabilitação funcional ou readaptação ocupacional das pessoas atingidas por uma patologia e, ainda, os controles de água e alimentos nos parâmetros influentes da saúde pública.

A história das profissões das tecnologias da saúde, enquanto áreas científicas e áreas profissionais, e o próprio desenvolvimento profissional daqueles que as exercem, é uma área de estudo muito pouco explorada em Portugal (Coutinho, 2011).

A sua identidade profissional evoluiu ao longo deste século (Tavares, 2007), vindo a assumir características diferentes de acordo com o país onde se desenvolvem, a sua história e organização social. No entanto, é actualmente inegável o seu contributo na prestação de cuidados de saúde e para melhoria da qualidade de vida das populações (Coutinho, 2003).

A evolução e afirmação destas profissões no nosso país, e no plano internacional, têm sido progressivas. Porém, os PTS, hoje, exercem as suas actividades na tensão entre serem profissionais auxiliares do médico (MS 2010) ou serem profissionais autónomos com saberes e competências próprias que não competem com os de nenhum outro profissional de saúde, antes realizam actividades essenciais e, dessa forma, se constituem como profissionais chave para a integração dos processos de cuidado e compõem as equipas de prestadores com igual capacidade e elevado potencial de desenvolvimento.

Aliás, noutros países, estes profissionais, nomeadamente os fisioterapeutas, são vistos como profissionais de primeiro contacto sem intermediação de médicos especialistas (Estêvão, 2006, Coutinho, et al., 2010).

Em Tecnologias da Saúde as metodologias emergentes, geralmente, não substituem as existentes, antes se lhes adicionam acrescentando a panóplia de recursos diagnósticos ou terapêuticos disponíveis.

A radiologia, por exemplo evoluiu, até na designação da atividade, para imagiologia por força da diversidade de métodos de captação de imagem e do suporte em que esta se fixa que, de uma tomada por raios $\mathrm{X}$ - um restrito intervalo de comprimentos de onda energética - e revelação em suporte e técnica fotográficos permitindo apenas visualizar o esqueleto, passaram a ser captadas pela incidência de variantes comprimentos de onda ou mesmo de electromagnetismo e indução de alterações, extremamente ténues e transitórias, na conformação molecular ou na fisiologia celular, detectáveis apenas por meios de intensificação electrónicos, informaticamente suportados e telematizáveis a distância. 


\section{Conceição Assis Pacheco e Albino Lopes}

Os meios de diagnóstico laboratorial incorporaram as descobertas das áreas da bioquímica e das biologias, celular e molecular, não só alargando os corpos e componentes celulares detectáveis, mas também adoptaram processos, enzimáticos e imunológicos, miméticos dos processos biológicos que acrescentaram de forma logarítmica o número e variedade de moléculas biológicas determináveis para fins diagnósticos. Não menores foram os avanços na microbiologia que permitem hoje a identificação precoce, e diferencial, de agentes etiológicos de existência insuspeitável há poucos anos.

Mesmo as terapias manuais acompanharam e adaptaram-se à evolução científica, nomeadamente na área da neuromedicina, e evoluíram em consonância.

Ser PTS hoje requer capacidade de adquirir novos conhecimentos à mesma velocidade que qualquer médico na sua especialidade pois que a especificidade do diagnóstico ou da terapêutica implicam o domínio da ciência que as subjaz. O modelo integrado de ensino para estas profissões, iniciado em $1980^{7}$ - há já três décadas - constitui-se, em termos europeus, como um padrão.

A despeito da evidente recomposição profissional induzida pelo agrupamento e pela constante adaptação dos modelos de ensino às necessidades do mercado de trabalho, estas profissões são ainda consideradas emergentes discutindo-se a sua consolidação sociológica com conclusões que tendem a inclui-las na categoria de «quasiprofissões» (Rodrigues, 2002) claramente dissonantes da realidade organizacional, da sua história e da construção legal que as suporta ${ }^{8}$. Da ideologia vigente resulta a asfixia do potencial de desenvolvimento destas profissões.

Ademais, as suas atividades, fundamentais como demonstrado, são também grandes utilizadoras de recursos financeiros e, por tal, responsáveis por uma fatia muito considerável dos gastos em saúde.

\subsection{Dimensão política}

A multiplicidade de saberes biomédicos tem-se expandido de tal forma que nenhum humano consegue abarcar toda a sua extensão para a aplicar ao exercício de uma profissão, nem mesmo os médicos. Por isso se assiste, necessariamente, à diferenciação de várias profissões nas áreas

\footnotetext{
${ }^{7}$ Port $^{\mathrm{a}}$ 709/80, de 23-9

${ }^{8}$ DL's 261/93, de 24-7 e 320/99, de 11-8.
} 
da saúde. Cuidar de um doente e tratar a patologia que apresenta, ou manter a saúde e reinserir funcionalmente, são, hoje, de forma incontornável, tarefas multidisciplinares e multiprofissionais (Pais Ribeiro \& Leal, 2011) em que as ciências e tecnologias da saúde, e os PTS, assumem um papel principal.

E se as pessoas, profissionais de saúde e população, já não dispensam a fundamentação das decisões clínicas sem o recurso aos meios de diagnóstico disponíveis e não prescindem dos actos terapêuticos que fomentam a sua qualidade de vida, a boa gestão dos recursos aplicados (capital de conhecimento, financeiro e, no seu cerne, os recursos humanos) é fulcral para a economia da saúde.

Ora, assim sendo, há que fazer-se uma gestão estratégica destes recursos humanos detentores de conhecimento de ponta, cuja actividade subjaz qualquer acto de saúde, e, dada a complexidade envolvida, e a comprovação aportada pela ineficácia consabida das estratégias de gestão que têm vindo a ser levadas a cabo, pois que o paradigma que as ilumina e as práticas que lhes são associadas no que a estas profissões tange, ao querer reduzir os profissionais a meros operacionais na organização de saúde (MS, 2010), não é sustentável.

Há portanto, que ceder a quem conhece a autonomia necessária à boa aplicação dos recursos (Nunes, 2007), que são, conhecida e declaradamente, escassos.

E esta cedência só pode fazer-se pelo reconhecimento de que os saberes detidos e as competências demonstráveis apenas esperam a oportunidade para emergir na constituição de equipas multidisciplinares mas que concedam «o seu a seu dono», passando pelo aplanamento das actuais estruturas hierárquicas e pelo abandono do paradigma gestionário de «comando e controle» pela classe médica (MS, 2010), sem substituir estes mandantes pelos da classe de enfermagem.

O equilíbrio de poderes no sistema de saúde muda quando se almeja prestar melhores cuidados sem desperdício de recursos, escassos sim mas sobretudo, crescentemente onerosos. Os sistemas sociais não são constituídos por redes físicas ligando as partes mas por processos comunicacionais entre essas partes concretizados na interacção entre elas (Pena Pires, 2007). Tais processos não são unívocos nem simétricos antes são ambíguos, polissémicos, hierarquizados e manipuláveis.

A recusa sistemática por parte das administrações hospitalares e dos estrategas da saúde em reconhecer a fulcral importância das profissões 
das TS para o sistema, e dos saberes que os PTS já demonstram, postergando a sua integração como pares nas equipas mais não tem feito que adiar uma inevitabilidade (Johnson, Dowd \& Ridgeway, 2006) e demonstrar a divergência entre a realidade profissional e organizacional e as teorias que fundam as racionalidades.

A despeito de, desde $1977^{9}$, estas actividades, e apesar da sua diversidade, terem sido englobadas num único grupo profissional, ainda hoje, os PTS vivem posicionados entre dois precipícios: o da desagregação do grupo nas várias profissões que o integram e a necessidade de coesão num mesmo grupo profissional para atingir massa crítica que faça pender as relações de poder na organização para um equilíbrio que tenha como um dos pilares estas actividades de que já não pode, hoje, prescindir-se nos cuidados em saúde.

Por outro lado, o processo de Bolonha, e a confirmação de 240 ECTS - em $2009^{10}$ - como mínimo necessário ao desenvolvimento das competências básicas para o exercício profissional, obriga a uma validação da posição destes profissionais na estrutura organizacional que tem vindo a ser-lhes negada pelos poderes mais tradicionais e mais enraizados.

Além disso, neste contexto de poupança obrigatória de recursos escassos, os PTS constituem um elo chave já que são diretamente responsáveis por algumas das mais dispendiosas atividades em saúde e, simultaneamente, detêm os conhecimentos bastantes para regular o uso dos recursos e, assim, introduzir racionalidade, sem perca de qualidade nem adequação na prestação de serviço às pessoas, e, nesse passo, gerar mais-valias no sistema, de retorno avultado, por simples diminuição de desperdícios, de valor elevado.

Ainda, por um lado, o crescente interesse dos sectores privado, e social, por esta área de negócio, por outro, o aumento da circulação de informação com consequente progressiva diminuição da assimetria de informação do cliente e, ainda por outra perspetiva, o incremento das técnicas de marketing para criar novos nichos de necessidades de saúde na população e manter a tensão virtual entre o que as pessoas pensam que sabem e o que as pessoas supõem ainda ter que saber para não incorrer em erros que ponham em causa a sua longevidade, a sua sobrevida e o seu bem-estar "eterno" forçam um aprofundamento da complexidade

\footnotetext{
${ }^{9}$ Decreto Regulamentar 87/77, de 30/12

${ }^{10}$ Portaria 505-D/99, de 15 de Julho e Dec-lei de 2009, respetivamente
} 
(Escoval \& Campos Fernandes, 2010) nesta área, insuspeito até há pouco tempo.

Há que incorporar uma realidade ainda mal reconhecida mas que é charneira na Gestão de Recursos Humanos em saúde porque as actividades desenvolvidas pelos PTS são indução e fundamento de decisões cruciais em medicina e enfermagem pelo que se tornam imprescindíveis no cuidar.

\subsection{Gestão de Recursos Humanos}

A questão primacial nas OSS prende-se, na verdade, com as matérias de concentração/delegação de poderes (Pita Barros, 2007, Carvalho, 2008) e com a evidência da necessidade de partilha desse poder e, portanto, da sua redistribuição. Os argumentários ainda se fundam no princípio da legalidade e escudam-se em conceitos sociológicos obsoletos para estribar decisões (MS, 2010) mais do que no princípio da liberdade e na adaptação contingente à realidade (Correia de Campos, 2008).

Contudo, a introdução constante de novas tecnologias nas actividades de diagnóstico ou terapêutica não vai substituir os profissionais de saúde, antes irá libertá-los para o exercício do seu core business - cuidar de Pessoas, prevenir, rastrear, diagnosticar, recuperar, reinserir. Em suma, tratar doentes e doenças e manter ou restabelecer a saúde (ACS, 2009), o que, afinal, compõe a missão que os profissionais de saúde aceitam adoptar no dia em que escolhem trilhar a sua via de vida.

Até agora, a evolução do sistema de saúde, no que respeita às relações entre os múltiplos grupos profissionais que cumprem a missão de cuidar, tem sido no sentido da desintegração.

As profissões das Tecnologias da Saúde são evolutivas em função da volatilidade dos meios técnicos que utilizam e das ciências que as suportam, e têm constituído um pólo de mais desintegração no sistema ao instituírem mais um núcleo de poder grupal na organização.

Porém, as diferenças inerentes à multiplicidade de actividades que realizam e à crescente especialização necessária para fazer face à evolução da tecnologia que as confirma e das necessidades em saúde que as justificam, podem vir a induzir também a desagregação do grupo de profissões. 
E, assim, a totalidade da organização corre o risco de se desarticular até porque uma das características das OSS é serem burocracias profissionais, imperfeitamente conectadas (Nunes, 1994).

Para o contrariar, torna-se imperioso um paradigma de GRH que, para além de deixar de ver os profissionais como instrumentais às actividades e à organização, os assuma como partes interessadas no sucesso (Escoval \& Campos Fernandes, 2010) e numa prestação de serviço público meritocrática e de excelência.

Por outro lado, a multiplicação de actividades e de interventores nos processos de gestão de doentes e promoção da saúde enfraquece os argumentos de exclusividade de ação, legitimidade, ou insubstituibilidade dos saberes porque os distribui e difunde, mas sobretudo, a democratização da informação e do conhecimento em saúde através da comunicação social, das redes electrónicas, do marketing, ou mesmo por formas mais informais, acarreta o empowerment do cliente, a despeito dos dispositivos de inércia e manutenção da situação que estejam montados. E estas dimensões vêm alterar os equilíbrios existentes, para benefício do sistema.

Torna-se imprescindível considerar as tecnologias de saúde e as de informação para uma análise estratégica, integradora do sistema. As tecnologias são as grandes esquecidas nessa ponderação (McKee et al., 2004).

Todos os sistemas têm diversos pontos de sustentação que permitem a edificação e a sua consolidação e, em sistemas com o nível de complexidade que caracteriza o da prestação de cuidados de saúde, eles são, naturalmente, múltiplos. Mas a Saúde é, ainda, pensada e governada como se fosse uma entidade unipode.

O paradigma que enforma a prestação de cuidados mantém-na, para além de hospitalocêntrica, médicocêntrica (MS, 2010). A solidez do poder médico sustém a sua própria derrocada e mantém a estrutura porque as relações sociais que cimentam o estado da situação se mantêm. (Carapinheiro, 2005; Areosa \& Carapinheiro, 2008).

Porém, pela expansão exponencial das ciências e do saber biomédico, essa unipodia não sustenta o edifício por muito mais tempo, antes vacila aos embates do desenvolvimento dos saberes profissionais dos outros elementos e aos saberes leigos dos clientes/utentes/doentes.

O SNS, afinal, ainda é um conjunto de mundos incomunicantes (Carapinheiro, 2005). Todos competindo por mais qualificação, por mais visibilidade, por mais carreira, por mais estatuto. Incapazes de cooperar. 
Vivendo por entre estes mundos o doente, fulcro retórico da atividade, intento da qualificação e objecto de todo o saber, encontra-se arredado para as franjas do sistema, quando deveria ter trato de convidado (guest), ser central aos interesses e a toda a realização. Na impossibilidade de penetrar na profundidade de tais saberes vê-se manietado por peritagens, desapossado do direito a pensar, aprender e controlar os procedimentos a que é sujeito "pela sua saúde", como diz o slogan.

Segundo Lopes e Barrosa, (2008) na actual conjuntura a GRH é mais uma questão de filosofia e de princípios do que de instrumentos, visto que estes estão desenvolvidos e testados empiricamente e se fundam em modelos validados pelas práticas.

A adopção de uma racionalidade estratégica na Gestão destes Recursos Humanos pelo reconhecimento do património de saberes detidos, da sua apropriação pelas OSS e da sua certificação e gestão como capital intelectual (Matos \& Lopes, 2008) uma vez que a produção deste conjunto de profissionais é um fator determinante nas atividades em saúde e altamente qualificada.

A dificuldade da GRH nas OSS será a de reunir grupos multidisciplinares (Dussault \& Fronteira, 2010) capazes de definir expectativas positivas, centrar a sua acção em objetivos profissionais mas, e sobretudo, no fim social que é inerente ao seu papel enquanto profissionais.

O objetivo da GRH nas OSS será, assim, construir equipas, fornecerlhes os recursos para a auto-sustentabilidade, obter feedback para poder avaliar constantemente as realizações (Dussault e Fronteira, 2010) e disponibilizar oportunidades de coaching para a manutenção do elevado desempenho.

\section{MÉTODO}

\subsection{Metodologia}

Tratando-se de uma questão de investigação que se assume como uma antevisão de futuros possíveis numa realidade mutante, forçosamente tínhamos que aceitar realizar uma metodologia de análise orientada para o futuro (Mateus Marques, 2007).

Seria inviável a construção da investigação enquadrada numa tecnologia de observatório (do inglês «technology of foresight») (Martin, 
2001), ou conformada por uma matriz de previsão estratégica como seria ideal, dada a impossibilidade de recrutar os meios necessários. Assim, para alcançar os objectivos a que nos propomos e porque é um método adequado à extensão e profundidade procuradas para a presente investigação escolhemos aplicar o método de Painel de Delphi.

Esta técnica é definida como um método para estruturar o processo de comunicação em grupo para que seja efetivo permitindo a um grupo de pessoas, como um todo, lidar com um problema complexo.

Delphi é uma das metodologias científicas que possibilita analisar dados qualitativos. Trata-se de um método que permite descobrir as opiniões de especialistas - no seu conjunto denominado de painel delphi. Não requer interação face-a-face e usa uma série de questionários de resposta anónima, entre os participantes, através da elaboração, pelo observador, de relatórios para um feedback controlado dos resultados consolidados a partir das respostas precedentes com o uso de ferramentas estatísticas simples (Alvarenga et al., 2007).

É um método qualitativo, exploratório, de tomada de decisão em grupo, estruturado e que põe em evidência conhecimento implícito porque facilita a ponderação de um problema complexo e a deteção de padrões de acordo entre pessoas que não se conhecem.

\subsection{Procedimento}

A partir das pronúncias totalmente livres de um primeiro grupo de sete (7) peritos - gestores, professores de TS, PTS's com funções de responsabilidade, sindicalistas - a uma série de sete (7) questões genéricas e abrangentes das matérias, foi realizada uma análise das respostas recebidas por via electrónica e elaborado, por análise de conteúdo, um primeiro agregado de proposições e resenha que foi devolvida aos respondentes para feedback do resultado. A partir das proposições apuradas na primeira fase do painel desenvolveu-se um questionário composto por 66 questões que foi submetido a um outro conjunto de peritos - desta vez, catorze (14) peritos entre PTS e gestores - que a elas responderam na presença do investigador que colheu os comentários que se lhes apresentaram como oportunos acerca da pertinência e adequação dos itens e da relevância das matérias em estudo.

Não se colocaram problemas éticos uma vez que os elementos integrantes do painel de Delphi foram convidados e lhes foi dada liberdade de expressão de posições e opiniões. 


\section{RESULTADOS}

Assim, das opiniões dos especialistas resultou um instrumento de 61 questões ${ }^{11}$ que se apresenta em anexo e ficou constituído da seguinte forma: 21 questões de caracterização do trabalho em TS; 13 de análise da realidade da GRH em relação aos PTS; 9 que procuram apurar o que pensam os profissionais do futuro das várias profissões; 18 de caracterização dos atributos sócio-demográficos dos respondentes.

Destes, 37 requerem resposta com o uso de uma escala de Likert de cinco pontos, mesmo se permite a proteção de um ponto médio que optámos por manter para maior descriminação das respostas e avaliação das respostas defensivas que, caso se verifiquem com significância estatística, podem ser indicativas de problemas identitários ou de integração na estrutura organizacional.

A codificação das respostas varia, por questões de semântica e legibilidade por parte do respondente, maioritariamente entre «discordo totalmente» e «concordo totalmente». Quatro dos itens adoptam a codificação de «nada» a «totalmente» e outros quatro adoptam a de «nenhuma importância» a «muita importância». A questão 17, com 10 itens, adopta os códigos de «nada» a «fundamental». Restam 6 itens de resposta alternativa (sim/não) por apenas nos interessar saber se existe ou não a tendência ou, no caso da questão 8 , os seus 8 itens são suficientemente diferenciadores para eliminar a necessidade de uma escala mais alargada.

As 21 questões de caracterização do trabalho em TS dividem-se em: natureza da posição profissional (3 itens; 1,3 e 5); consolidação da posição (2 itens; questão 8 com 8 itens e item 15); diferenciação profissional (2 itens; 2 e 4); fronteiras entre profissões (2 itens; 6 e 7 que apenas é respondido se houver concordância na anterior); autonomia no seio dos grupos de trabalho (1 questão com 6 itens; 9); interdependência do trabalho (1 item; 10); diferenciação do trabalho (itens 11, 12, 13 e 14 interrelacionados e diferenciando saberes técnicos de conhecimentos e

\footnotetext{
${ }^{11}$ Dos 66 itens iniciais, 5 vieram a ser excluídos por redundantes, apresentarem complexidade de resposta para resultados incertos ou incidirem sobre matéria irrelevante. As questões foram ainda reordenadas para melhor compreensão do racional fundador, fluidez e coerência.
} 
competências); instrumentalidade da profissão (2 itens; 16 e17); e, relevância para os clientes/integração no Sistema (4 itens;18, 19, 20 e 21). $\mathrm{O} \alpha$ de Cronbach, standardizado, obtido para a totalidade destes itens, num total de 49 variáveis, foi de 0,699 .

Os 13 itens seguintes estudam as condições em que se concretiza a GRH em questões atinentes aos PTS, nomeadamente: consulta dos profissionais em matérias de GRH (itens 22, 23 e 24; representação nos níveis de gestão (item 32, 33 e 34); necessidade de formação pósgraduada para funções de gestão (item 25); e preparação para funções de gestão (item 26). Inquirem ainda sobre a conjuntura actual (item 27 e 28); sobre os paradigmas que enformam a gestão na organização onde exercem (itens 29, 30 e 31); e, qual o nível de cumprimento da norma legal quando à estrutura profissional na organização (itens 32,33 e 34).

$\mathrm{Na}$ matéria os PTS e o futuro, o item 36 refere-se às fronteiras entre as várias profissões das TS; as questões 35 e 39 orientam-se para as fronteiras de actividade com outras profissões; as questões 37, 40 e 42 preocupam-se com a adequação da formação às necessidades; e, as questões 38 e 41 concernem a identidade para a sustentabilidade.

Por fim a extensa caracterização da amostra (18 itens) é determinada pela diversidade de situações que a rápida evolução da formação e do desenvolvimento profissional produziu e que, com grande probabilidade, ainda coexistem nas organizações, facto que é fundamental apurar.

Por tal razão, esperamos vir a encontrar estratificação na amostra em função das variáveis sócio-demográficas que permitirá desvelar alguns dos alicerces do real que é objetivo do estudo.

\section{CONCLUSÕES}

Este trabalho possibilita uma análise detalhada do estado de desenvolvimento dos PTS e da sua integração no SS. Dessa forma contribuirá para o conhecimento da realidade no que a estas profissões concerne e facilitará a sua inclusão nos estudos prospectivos que o OPSS aconselha (OPSS, 2011)

A racionalidade gestionária que impera no Sistema de Saúde fragmenta o todo e fomenta a competição (Carapinheiro, 2005), logo é paramétrica e desintegrativa. Por esse facto, há que instaurar uma racionalidade estratégica, matricialmente alinhada, fundada num ideário de relações humanas paritárias e de confiança, processos internos consensualmente controlados, objetivos coletivos e adhocraticamente 
(Mintzberg, 2004) programados, estímulo à inovação e iniciativa individual e grupal, integração das partes e regulação retrógrada.

À GRH caberá detetar pontos nodais (Gratton \& Truss, 2003) e gerir coordenando pilares (Lopes \& Barrosa, 2008), ativar a comunicação intergrupal, estimular as autonomias e instaurar a confiança através da constituição de uma comissão consultiva com um programa de previsão estratégica com a aplicação de tecnologias de foresight (WHO, 2006; Dussault \& Fronteira, 2010).

O instrumento que resultou deste trabalho visa desenvolver indicadores de caracterização do grupo de profissões das TS, conhecer da realidade profissional, descrever o estado de desenvolvimento socioprofissional dos PTS e estudar áreas de fronteira de atividades.

Assim, permitirá que, no futuro, venha a ser possível estudar com maior profundidade o poder intraorganizacional e as suas relações com a estrutura e as faces ocultas e mudas (Lopes, 2011) que aí se abrigam, desnudar os efeitos da emergência de novos grupos profissionais e os fatores de resistência ao surgimento de profissões que ameaçam as bases de poder das profissões instaladas.

No que aos PTS diz respeito, haverá que estudar por que vias procuram preservar a sua autonomia e incrementar o controlo sobre a sua actividade.

Será ainda necessário realizar estudos sobre as dinâmicas assumidas pelos grupos profissionais perante os acontecimentos que limitam a influência dos grupos tradicionais.

Em suma, fala-se do Sistema de Saúde de uma forma abstrata, constroem-se paralelos com outras realidades mas não se começa pelo básico, isto é, as perguntas: Como é, realmente, a estrutura das OSS portuguesas, que grupos profissionais aí laboram, como se posicionam entre si, que perfil de capacidades demonstram. Em Saúde, parte-se para a análise, com dados adquiridos e não se questiona a realidade organizacional. Há que fazê-lo. Este instrumento é um contributo para esse esforço. Constitui um estudo germinal que, por ser isso mesmo, se deparou com limitações incontornáveis ligadas à novidade do tema e à complexidade do campo de estudo. Contudo é apenas o início de um caminho que se está a trilhar. 


\section{Agradecimentos}

A autora expressa o seu agradecimento aos peritos que integraram o painel de Delphi cujas contribuições foram fulcrais para o desenvolvimento do instrumento apresentado.

\section{FONTES E BIBLIOGRAFIA}

Acs, Alto Comissariado da Saúde., (2009). Estratégias de Saúde em Portugal - O Plano Nacional de Saúde 2004/2006. Lisboa: Alto Comissariado da Saúde.

Alvarenga, A., carvalho, P.S., \& escária, S.C., (2007) Delphi - Método e Aplicações. Departamento de Prospectiva e Planeamento, Ministério do Ambiente, do Ordenamento do Território e do Desenvolvimento Regional.

Antunes, M., (2001), A doença da Saúde - Serviço Nacional de Saúde: ineficiência e desperdício, Lisboa: Quetzal Editores e Fundação Calouste Gulbenkian.

Antunes, M., (2006). Reformar a Saúde em Portugal in O Futuro da Saúde em Portugal. APDH (Org.). Companhia das Ideias: Lisboa.

Areosa, J. \& Carapinheiro, G., (2008). Quando a imagem é profissão Profissões da imagiologia em contexto hospitalar, Sociologia, Problemas e Práticas 57, 83-108.

Carapinheiro, G., (2005), Saberes e Poderes no Hospital: Uma sociologia dos serviços hospitalares, $4^{\text {a }}$ edição, Porto: Edições Afrontamento.

Carapinheiro, G., (2006) A Saúde enquanto matéria política, G. Carapinheiro (Org.) Sociologia da Saúde: Estudos e perspectivas, Coimbra: Pé de Página Editores, Lda.

Cardim, J. C. \& Miranda, R. R., (2007)., O Universo das Profissões: Da qualificação às competências e à evolução profissional. Lisboa: ISCSP-UTL.

Carvalho Rodrigues, L., Ginó, A., Sena, C. \& Dahlin, K., (2002). Compreender os Recursos Humanos do Serviço Nacional de Saúde, Lisboa: Edições Colibri/Apifarma.

Carvalho, M. J., (2008). Gestão e Liderança em Saúde - Uma abordagem estratégica. Vida Económica: Porto.

Conde, J., (2006). O Ensino Da Saúde Em Portugal: O Escândalo Instalado Nas Tecnologias da Saúde. Coimbra: ESTeSC - IPC. 
Correia de Campos, A., (2008). Reformas da Saúde - O fio condutor. Coimbra: Almedina.

Coutinho, I., (2003). Atitudes dos Fisioterapeutas Face aos Padrões de Prática em Fisioterapia. Dissertação apresentada para realização de Provas Públicas a Professor-Coordenador. Lisboa: ESTeSL - IPL.

Coutinho, I., (2011). Perfis Comportamentais dos Fisioterapeutas: Estudo comparativo entre fisioterapeutas em dois momentos da sua carreira em relação a vários parâmetros comportamentais atitudinais, posturais, antropométricos e de patologia clinica. Tese de Doutoramento em Ciências do Desporto. Bragança: UTAD. (texto policopiado)

Coutinho, I., Silveira Sérgio, J.A., Paiva de Sá, N.M. F. \& Salgueiro, L.F.M., (2010). Contributos para a historiografia da fisioterapia em Portugal. Fisioterapia Brasil - Volume 11 - Número 6 novembro/Dezembro.

Dias, A., \& Santana, S., (2009). Cuidados integrados: Um novo paradigma na prestação de cuidados de saúde. Rev. Portuguesa e Brasileira de Gestão, mar.2009, vol. 8, $n^{\circ}$ 1, p.12-20.

Dussault, G. \& Dubois, C-A., (2003). Human Resources for Health Policies: A critical component in health policies. Human Resources for Health, I: 1 .

Dussault, G. \& Fronteira, I., (2010). Human Resources for Health (HRH) Plan Component of National Health Plan 2011-2016 (Portugal). Documento de Trabalho Plano Nacional de Saúde. Lisboa: ACS

Escoval, A. \& Campos Fernandes, A., (Coord.). (2010). Plano Nacional de Saúde 2011-2016: Cuidados de Saúde Hospitalares. Lisboa: ACS, MS e PNS.

ESTeSL (ESCOLA SUPERIOR DE TECNOLOGIA DA SAÚDE), (2007). ESTeSL: Um breve olhar sobre os 25 anos de Ensino e Formação. Lisboa: ESTeSL-IPL.

Estevão, H., (2006). O que eles pensam e sabem sobre a fisioterapia e os fisioterapeutas. Monografia de pós-graduação em Gestão e Administração da Saúde. Lisboa: ESTeSL-IPL (texto policopiado).

Felício, M.J., Lopes, A., Salgueiro, F., \& Parreira, P., (2007). Competências de gestão: Um instrumento de medida para a realidade portuguesa. Rev. Portuguesa e Brasileira de Gestão. Jul. 2007, vol.6, n. ${ }^{\circ} 3$, p.18-30. 
Gratton, L. \& Truss, C., (2003). The Three-dimensional People Strategy: Putting human resources policies into action. Academy of Management Executive, vol. 17, $\mathrm{n}^{\circ} 3$.

Johnson, C., Dowd, T.J. \& Ridgeway, C.L., (2006). Legitimacy as a Social Process. Annu. Rev. Sociol. 32: 53-78.

Lobato, J.C., (2001). Contributos para o Desenho da História das Tecnologias da Saúde. Lisboa: ESTeL

Lopes, A., (2011). Cultura de Liderança versus liderança da Cultura Associada à Estrutura Burocrática-Mecânica: Uma contribuição da Teoria do Comportamento Organizacional para a identificação do problema da eficácia das organizações em Portugal. Lição de Sapiência na abertura do ano lectivo 2010/2011 ISCSP-UTL, 18 de Janeiro de 2011 (texto policopiado);

Lopes, A. \& Barrosa, L., (2008). A Comunidade Educativa e a Gestão Escolar: Um contributo da gestão estratégica de recursos humanos. Ramada: Edições Pedago, Lda.

Lopes, A.M.F., (Org.),(2004). Implementação do Processo de Bolonha a Nível Nacional, por Áreas de Conhecimento: Tecnologias da Saúde, Novembro. Lisboa: MCTES.

Lopes, N., (2001) Recomposição profissional da enfermagem: Estudo sociológico em contexto hospitalar, Coimbra: Quarteto Editora.

Lopes, N. (2006) Tecnologias da saúde e novas dinâmicas de profissionalização, em G. Carapinheiro, (Org.) Sociologia da Saúde: Estudos e perspectivas, Coimbra: Pé de Página Editores, Lda.

Lourtie, P., \& Pinto, M.L.R., (2007). Adequação do Cursos de Tecnologias da Saúde: Relatório para o Ministério da Saúde. Lisboa: Ministério da Saúde, Instituto Superior Técnico, Maio.

Mateus Marques, R., (2007). Contributo para a Organização da Urgência de Imagiologia de um Hospital Central. Tese de Doutoramento em Gestão. Lisboa: ISCTE Business School (texto policopiado).

Matos, F. \& Lopes, A., (2008). Gestão do Capital Intelectual: A nova vantagem competitiva das organizações. Comportamento Organizacional e Gestão, vol.14, $n^{\circ}$ 2, 233-245.

Martin, B.R., (2001). Tecnhnology Foresight in a Rapidly Globalizing Economy. Working Paper.

Martin, G.P., Currie, G. \& Finn, R., (2009), Reconfiguring or Reproducing intra-professional boundaries? Especialist Expertise, 
generalist Knowledge and the 'Modernization' of the Medical Workforce, Social Science and Medicine 68, 1191-1198.

Mckee, M., Edwards, N. \& Wyatt, S., (2004), Transforming Today's Hospital to Meet Tomorrow's Needs, Revista Portuguesa de Saúde Pública, volume temático: 4, Administração Hospitalar, 21-27.

Ministério da Saúde - Grupo Técnico para a Reforma da Organização Interna dos Hospitais (2010). A Organização Interna $e$ a Governação dos Hospitais.

Mintzberg, H., (2004). Pouvoir et Gouvernement d'Entreprise. Paris: Éditions d'Organization.

Nascimento, J. L., Lopes, A., \& Salgueiro, M. F., (2008). Estudo sobre a validação do "Modelo de Comportamento Organizacional" de Meyer e Allen para o contexto português. Comport.Organ.Gest., Abr. 2008, vol.14, $n^{\circ} 1$, p.115-133. ISSN 0872-9662.

Nunes, F., (1994) As Organizações de Serviços de Saúde: Alguns elementos distintivos, Revista Portuguesa de Gestão, III/IV, 5-28, Lisboa:ISCTE.

Nunes, P., (2007). Um Futuro para a Saúde? In O Futuro da Saúde em Portugal. APDH (Org.). Companhia das Ideias: Lisboa.

OPSS (Observatório Português dos Sistemas de Saúde), (2008). Relatório de Primavera: Sistema de Saúde Português - Riscos e Incertezas. Lisboa: OPSS.

OPSS, (2009) Relatório de Primavera - 10 Anos OPSS, 30 Anos SNS: Razões para continuar. OPSS: Lisboa.

OPSS (Observatório Português dos Sistemas de Saúde), (2011). Relatório de Primavera - Da Depressão da Crise Para a Governação Prospectiva da Saúde. OPSS: Lisboa

Pais Ribeiro, J. L., \& Leal, I. M. P., (2011). Psicologia da Saúde: Emergência e actualidade In Pereira Lopes, M. Jardim da Palma, P., Bártolo-Ribeiro, R. \& Pina e Cunha, M. (Coords.) Psicologia Aplicada. Lisboa: Editora RH

Pena Pires, R., (2007), Arvores Conceptuais - Uma reconstrução multidimensional dos conceitos de acção e de estrutura, Sociologia, Problemas e Práticas 53, 11-50.

Pita Barros, P. \& Simões, J. A., (2007). Portugal: Health System Review in Allin, S. e Mossialos, E. (Eds.) Health Systems in Transition vol. $9, n^{\circ} 5$. 
Proença, J., Morais Vaz, A., Escoval, A., Candoso, F., Ferro, D., Carapeto, C., Guedes Costa, R., Faujour, V., \& Roeslin, N., (2000). O Hospital Português: Os profissionais de Saúde - A gestão e o utente. Porto: Vida Económica Confer Forum.

Rego, A. \& Pina e Cunha, M., (2007) O Tao da Eficácia Organizacional: 18,5 Lições de gestão inspiradas no Velho Mestre. Lisboa: Edições Silabo.

Reis, V., (2007), O Sistema de Saúde em Portugal in O Futuro da Saúde em Portugal. APDH (Org.). Companhia das Ideias: Lisboa.

Rodrigues, M. L., (2002). Sociologia das Profissões, Oeiras: Celta Editora.

Santana, R. \& Costa, C., (2008), A Integração Vertical de Cuidados de Saúde: Aspectos conceptuais e organizacionais, Revista Portuguesa de Saúde Pública, vol. temático, 7.

Serra, H., (2006), Da Tecnologia à Tecnocracia. Estratégias do poder médico no limiar das fronteiras entre especialidades: $\mathrm{O}$ caso da transplantação hepática, in G. Carapinheiro (Org.) Sociologia da Saúde: Estudos e perspectivas, Coimbra: Pé de Página Editores, Lda.

Simões, J., (2004), Retrato Politico da Saúde - Dependência do percurso e inovação em saúde: da ideologia ao desempenho, Coimbra: Almedina.

Stoleroff, A. \& Correia, T., (2008), A empresarialização do sector hospitalar público português: a desregulação do mercado de trabalho médico e os desafios sindicais para a sua re-regulação, CIES $e$ Working Papers, CIES-ISCTE.

Tavares, D., (2002). Um século de Vivências nas Tecnologias da Saúde: contextualização dos processos de transformação social in Cadernos ESTeSL, $n^{\circ} 2$ Junho, 19-25. Lisboa: ESTeSL.

Tavares, D., (2007), Escola e Identidade Profissional: O caso dos técnicos de cardiopneumologia, Lisboa: Edições Colibri/Instituto Politécnico de Lisboa.

Tavares, D., Lobato, J., Medeiros, N., Raposo, N. \& Denis Silva, T., (2002). Retrato Sociográfico dos Técnicos de Cardiopneumologia do Quadro do Serviço Nacional de Saúde em Portugal. Cadernos ESTeSL, $n^{\circ} 1$ - Abril. Lisboa: ESTeSL.

Vital, E., Baltazar, C., Gavinho C., \& Mendes I., (2006). O Processo de Profissionalização dos Fisioterapeutas Portugueses. Arquivos de Fisioterapia Vol.1, $n^{\circ} 2$. 
WHO (2006). Relatório Mundial de Saúde - Formulando Estratégias Nacionais para a Força de Trabalho em Saúde. Génova: WHO 


\section{ANEXO}

Com este questionário pretende-se recolher a opinião dos profissionais das Tecnologias da Saúde sobre diversos aspetos da sua profissão e do seu trabalho.

\section{O QUESTIONÁRIO É}

\section{ANÓNIMO}

A informação recolhida destina-se exclusivamente a ser trabalhada no âmbito de trabalho académico que a investigadora está a realizar.

Muito Obrigada pela sua colaboração

Conceição Assis Pacheco

Profissional de Análises Clinicas

Mestre em Gestão de Recursos Humanos

Doutoranda em Comportamento Organizacional

Maio 2012

PS - Sinta-se livre para acrescentar às suas respostas qualquer comentário ou justificação. Nesse caso acrescente folhas ao questionário se em suporte eletrónico ou utilize as margens ou verso das folhas se em suporte papel. 


\section{QUESTIONÁRIO}

1. Atualmente, o trabalho dos Profissionais das Tecnologias da Saúde (PTS) está subordinado ao controlo dos médicos

\begin{tabular}{|c|c|c|c|c|}
\hline $\begin{array}{c}\text { Discordo } \\
\text { totalmente }\end{array}$ & $\begin{array}{c}\text { Discordo } \\
\text { parcialmente }\end{array}$ & $\begin{array}{c}\text { Não } \\
\text { concordo } \\
\text { nem discordo }\end{array}$ & $\begin{array}{c}\text { Concordo } \\
\text { parcialmente }\end{array}$ & $\begin{array}{c}\text { Concordo } \\
\text { totalmente }\end{array}$ \\
\hline & & & & \\
\hline
\end{tabular}

2. Os PTS têm que centrar-se na dimensão técnica mais do que na relacional

\begin{tabular}{|c|c|c|c|c|}
\hline $\begin{array}{c}\text { Discordo } \\
\text { totalmente }\end{array}$ & $\begin{array}{c}\text { Discordo } \\
\text { parcialmente }\end{array}$ & $\begin{array}{c}\text { Não } \\
\text { concordo } \\
\text { nem discordo }\end{array}$ & $\begin{array}{c}\text { Concordo } \\
\text { parcialmente }\end{array}$ & $\begin{array}{c}\text { Concordo } \\
\text { totalmente }\end{array}$ \\
\hline & & & & \\
\hline
\end{tabular}

3. Para aumentar a sua autonomia, as profissões das Tecnologias da Saúde (TS) necessitarão de afirmar espaço próprio no campo biomédico e especializar-se fundamentalmente nos domínios técnicos e científicos da sua profissão

\begin{tabular}{|c|c|c|c|c|}
\hline $\begin{array}{c}\text { Discordo } \\
\text { totalmente }\end{array}$ & $\begin{array}{c}\text { Discordo } \\
\text { parcialmente }\end{array}$ & $\begin{array}{c}\text { Não } \\
\text { concordo } \\
\text { nem discordo }\end{array}$ & $\begin{array}{c}\text { Concordo } \\
\text { parcialmente }\end{array}$ & $\begin{array}{c}\text { Concordo } \\
\text { totalmente }\end{array}$ \\
\hline & & & & \\
\hline
\end{tabular}

4. O aumento de formação dos PTS no domínio das ciências humanas valoriza o exercício profissional

\begin{tabular}{|c|c|c|c|c|}
\hline $\begin{array}{c}\text { Discordo } \\
\text { totalmente }\end{array}$ & $\begin{array}{c}\text { Discordo } \\
\text { parcialmente }\end{array}$ & $\begin{array}{c}\text { Não } \\
\text { concordo } \\
\text { nem discordo }\end{array}$ & $\begin{array}{c}\text { Concordo } \\
\text { parcialmente }\end{array}$ & $\begin{array}{c}\text { Concordo } \\
\text { totalmente }\end{array}$ \\
\hline & & & & \\
\hline
\end{tabular}

5. A função central do PTS é realizar os exames prescritos por médicos

\begin{tabular}{|c|c|c|c|c|}
\hline $\begin{array}{c}\text { Discordo } \\
\text { totalmente }\end{array}$ & $\begin{array}{c}\text { Discordo } \\
\text { parcialmente }\end{array}$ & $\begin{array}{c}\text { Não } \\
\text { concordo } \\
\text { nem discordo }\end{array}$ & $\begin{array}{c}\text { Concordo } \\
\text { parcialmente }\end{array}$ & $\begin{array}{c}\text { Concordo } \\
\text { totalmente }\end{array}$ \\
\hline & & & & \\
\hline
\end{tabular}

6. Algumas das atividades que realizo deveriam ser da competência de outro profissional de saúde

\begin{tabular}{|c|c|c|c|c|}
\hline $\begin{array}{c}\text { Discordo } \\
\text { totalmente }\end{array}$ & $\begin{array}{c}\text { Discordo } \\
\text { parcialmente }\end{array}$ & $\begin{array}{c}\text { Não } \\
\text { concordo } \\
\text { nem discordo }\end{array}$ & $\begin{array}{c}\text { Concordo } \\
\text { parcialmente }\end{array}$ & $\begin{array}{c}\text { Concordo } \\
\text { totalmente }\end{array}$ \\
\hline & & & & \\
\hline
\end{tabular}

7. Se concorda, parcial ou totalmente, indique algumas dessas atividades e qual o profissional que deveria realizá-las (TSS, secretária de unidade, AAM, médico ou enfermeiro)

8. Na minha opinião, a licenciatura exigida para o exercício em TS elevou o prestigio profissional dos PTS junto de:

\begin{tabular}{|l|l|l|}
\hline Opinião pública & Sim $\rceil$ & Não $\rceil$ \\
\hline Médicos & Sim $\rceil$ & Não \\
\hline Enfermeiros & Sim $\rceil$ & Não \\
\hline
\end{tabular}


Conceição Assis Pacheco e Albino Lopes

\begin{tabular}{|l|l|l|}
\hline Outros Técnicos Superiores de Saúde & Sim $\rceil$ & Não $\rceil$ \\
\hline Doentes & $\operatorname{Sim}\rceil$ & Não \\
\hline Outros profissionais de Saúde & $\operatorname{Sim}\rceil$ & Não $\rceil$ \\
\hline Gestão da Instituição & $\operatorname{Sim}\rceil$ & Não $\rceil$ \\
\hline Poder Politico & $\operatorname{Sim}\rceil$ & Não \\
\hline
\end{tabular}

9. Considero que, no meu local de trabalho, os PTS são incentivados a

\begin{tabular}{|l|l|l|l|l|l|}
\hline & Nunca & $\begin{array}{c}\text { Rara } \\
\text { mente }\end{array}$ & $\begin{array}{c}\text { Por } \\
\text { Vezes }\end{array}$ & $\begin{array}{c}\text { Quase } \\
\text { Sempre }\end{array}$ & Sempre \\
\hline $\begin{array}{l}\text { Procurar aprofundar os seus } \\
\text { conhecimentos profissionais }\end{array}$ & & & & & \\
\hline Realizar trabalho de investigação & & & & & \\
\hline $\begin{array}{l}\text { Sentir-se individualmente } \\
\text { responsáveis pela qualidade dos } \\
\text { resultados }\end{array}$ & & & & & \\
\hline $\begin{array}{l}\text { Participar na conceção das formas } \\
\text { mais adequadas de organização do } \\
\text { trabalho }\end{array}$ & & & & & \\
\hline $\begin{array}{l}\text { Trabalhar em articulação com os } \\
\text { profissionais de outras unidades } \\
\text { funcionais }\end{array}$ & & & & & \\
\hline $\begin{array}{l}\text { Assegurar a autonomia das suas } \\
\text { competências específicas face ao } \\
\text { campo de competências dos outros } \\
\text { profissionais }\end{array}$ & & & & & \\
\hline
\end{tabular}

10. O trabalho dos PTS é independente do trabalho dos outros profissionais de saúde

\begin{tabular}{|c|c|c|c|c|}
\hline Nada & Muito pouco & Parcialmente & $\begin{array}{c}\text { Quase } \\
\text { totalmente }\end{array}$ & Totalmente \\
\hline & & & & \\
\hline
\end{tabular}

11. O trabalho dos PTS é diferente do trabalho dos outros profissionais de saúde

\begin{tabular}{|c|c|c|c|c|}
\hline Nada & Muito pouco & Parcialmente & $\begin{array}{c}\text { Quase } \\
\text { totalmente }\end{array}$ & Totalmente \\
\hline & & & & \\
\hline
\end{tabular}

12. Os saberes técnicos que um PTS tem que aplicar na sua atividade profissional são diferentes dos de qualquer outro profissional de saúde

\begin{tabular}{|c|c|c|c|c|}
\hline Nada & Muito pouco & Parcialmente & $\begin{array}{c}\text { Quase } \\
\text { totalmente }\end{array}$ & Totalmente \\
\hline & & & & \\
\hline
\end{tabular}

13. Os conhecimentos que um PTS tem que dominar para exercer corretamente a sua atividade profissional são diferentes dos de qualquer outro profissional de saúde

\begin{tabular}{|c|c|c|c|c|}
\hline Nada & Muito pouco & Parcialmente & $\begin{array}{c}\text { Quase } \\
\text { totalmente }\end{array}$ & Totalmente \\
\hline & & & & \\
\hline
\end{tabular}

14. As competências que um PTS tem que demonstrar na sua atividade profissional são diferentes das de qualquer outro profissional de saúde

\begin{tabular}{|c|c|c|c|c|}
\hline Nada & Muito pouco & Parcialmente & $\begin{array}{c}\text { Quase } \\
\text { totalmente }\end{array}$ & Totalmente \\
\hline & & & & \\
\hline
\end{tabular}


15. Só uma pessoa qualificada por uma escola superior detém os conhecimentos necessários ao exercício nas áreas das TS

\begin{tabular}{|c|c|c|c|c|}
\hline $\begin{array}{c}\text { Discordo } \\
\text { totalmente }\end{array}$ & $\begin{array}{c}\text { Discordo } \\
\text { parcialmente }\end{array}$ & $\begin{array}{c}\text { Não } \\
\text { concordo } \\
\text { nem discordo }\end{array}$ & $\begin{array}{c}\text { Concordo } \\
\text { parcialmente }\end{array}$ & $\begin{array}{c}\text { Concordo } \\
\text { totalmente }\end{array}$ \\
\hline & & & & \\
\hline
\end{tabular}

16. Em que medida os seguintes fatores contribuem para a minha satisfação, ou insatisfação, com a profissão

\begin{tabular}{|c|c|c|l|c|c|}
\hline & $\begin{array}{c}\text { Muita } \\
\text { insatisfação }\end{array}$ & $\begin{array}{c}\text { Alguma } \\
\text { insatisfação }\end{array}$ & Indiferente & $\begin{array}{c}\text { Alguma } \\
\text { satisfação }\end{array}$ & $\begin{array}{c}\text { Muita } \\
\text { satisfação }\end{array}$ \\
\hline O tipo de horário & & & & & \\
\hline Remuneração & & & & & \\
\hline Contacto com os doentes & & & & & \\
\hline $\begin{array}{c}\text { Contacto com outros } \\
\text { profissionais de saúde }\end{array}$ & & & & & \\
\hline $\begin{array}{c}\text { Ter que assumir } \\
\text { responsabilidades }\end{array}$ & & & & & \\
\hline $\begin{array}{c}\text { As competências que } \\
\text { permite desenvolver }\end{array}$ & & & & & \\
\hline $\begin{array}{c}\text { Grau de risco de } \\
\text { desemprego }\end{array}$ & & & & & \\
\hline $\begin{array}{c}\text { Poder contribuir para o } \\
\text { bem-estar dos outros }\end{array}$ & & & & & \\
\hline
\end{tabular}

17. O mais importante no meu trabalho é:

\begin{tabular}{|c|l|l|l|l|l|}
\hline & Nada & Pouco & $\begin{array}{c}\text { Relativa } \\
\text { mente }\end{array}$ & Muito & Fundamental \\
\hline O conteúdo do trabalho & & & & & \\
\hline A relação com o doente & & & & & \\
\hline As tarefas que realizo & & & & & \\
\hline Os conhecimentos que aplico & & & & & \\
\hline A autonomia com que exerço & & & & & \\
\hline A relação com os meus colegas & & & & & \\
\hline $\begin{array}{c}\text { A relação com outros colaboradores da } \\
\text { Organização }\end{array}$ & & & & & \\
\hline $\begin{array}{c}\text { O reconhecimento da importância das } \\
\text { minhas funções }\end{array}$ & & & & & \\
\hline A avaliação de desempenho que obtenho & & & & & \\
\hline A tecnologia em uso no meu serviço & & & & & \\
\hline
\end{tabular}

18. Penso que os doentes atribuem ao trabalho nas áreas de diagnóstico e terapêutica

\begin{tabular}{|c|c|c|c|c|}
\hline $\begin{array}{c}\text { Nenhuma } \\
\text { importância }\end{array}$ & $\begin{array}{c}\text { Pouca } \\
\text { importância }\end{array}$ & $\begin{array}{c}\text { Relativa } \\
\text { importância }\end{array}$ & $\begin{array}{c}\text { Bastante } \\
\text { importância }\end{array}$ & $\begin{array}{c}\text { Muita } \\
\text { importância }\end{array}$ \\
\hline & & & & \\
\hline
\end{tabular}

19. Penso que os outros profissionais de saúde atribuem ao trabalho nas áreas de diagnóstico e terapêutica

\begin{tabular}{|c|c|c|c|c|}
\hline Nenhuma & Pouca & Relativa & Bastante & Muita \\
\hline
\end{tabular}




\section{Conceição Assis Pacheco e Albino Lopes}

\begin{tabular}{|c|c|c|c|c|}
\hline importância & importância & importância & importância & importância \\
\hline & & & & \\
\hline
\end{tabular}

20. Penso que os médicos atribuem ao trabalho nas áreas de diagnóstico e terapêutica

\begin{tabular}{|c|c|c|c|c|}
\hline $\begin{array}{c}\text { Nenhuma } \\
\text { importância }\end{array}$ & $\begin{array}{c}\text { Pouca } \\
\text { importância }\end{array}$ & $\begin{array}{c}\text { Relativa } \\
\text { importância }\end{array}$ & $\begin{array}{c}\text { Bastante } \\
\text { importância }\end{array}$ & $\begin{array}{c}\text { Muita } \\
\text { importância }\end{array}$ \\
\hline & & & & \\
\hline
\end{tabular}

21. Penso que a gestão de topo da organização atribui ao trabalho nas áreas de diagnóstico e terapêutica

\begin{tabular}{|c|c|c|c|c|}
\hline $\begin{array}{c}\text { Nenhuma } \\
\text { importância }\end{array}$ & $\begin{array}{c}\text { Pouca } \\
\text { importância }\end{array}$ & $\begin{array}{c}\text { Relativa } \\
\text { importância }\end{array}$ & $\begin{array}{c}\text { Bastante } \\
\text { importância }\end{array}$ & $\begin{array}{c}\text { Muita } \\
\text { importância }\end{array}$ \\
\hline & & & & \\
\hline
\end{tabular}

22. A GRH deveria consultar os PTS em tudo o que respeite as tecnologias de diagnóstico ou terapêutica

\begin{tabular}{|c|c|c|c|c|}
\hline $\begin{array}{c}\text { Discordo } \\
\text { totalmente }\end{array}$ & $\begin{array}{c}\text { Discordo } \\
\text { parcialmente }\end{array}$ & $\begin{array}{c}\text { Não } \\
\text { concordo } \\
\text { nem discordo }\end{array}$ & $\begin{array}{c}\text { Concordo } \\
\text { parcialmente }\end{array}$ & $\begin{array}{c}\text { Concordo } \\
\text { totalmente }\end{array}$ \\
\hline & & & & \\
\hline
\end{tabular}

23. Deveria haver um representante permanente dos PTS na gestão da organização

\begin{tabular}{|c|c|c|c|c|}
\hline $\begin{array}{c}\text { Discordo } \\
\text { totalmente }\end{array}$ & $\begin{array}{c}\text { Discordo } \\
\text { parcialmente }\end{array}$ & $\begin{array}{c}\text { Não } \\
\text { concordo } \\
\text { nem discordo }\end{array}$ & $\begin{array}{c}\text { Concordo } \\
\text { parcialmente }\end{array}$ & $\begin{array}{c}\text { Concordo } \\
\text { totalmente }\end{array}$ \\
\hline & & & & \\
\hline
\end{tabular}

24. Deveria ser obrigatória a constituição, e funcionamento, de um Conselho das Tecnologias da Saúde que integrasse representantes das várias áreas de atividade em TS

\begin{tabular}{|c|c|c|c|c|}
\hline $\begin{array}{c}\text { Discordo } \\
\text { totalmente }\end{array}$ & $\begin{array}{c}\text { Discordo } \\
\text { parcialmente }\end{array}$ & $\begin{array}{c}\text { Não } \\
\text { concordo } \\
\text { nem discordo }\end{array}$ & $\begin{array}{c}\text { Concordo } \\
\text { parcialmente }\end{array}$ & $\begin{array}{c}\text { Concordo } \\
\text { totalmente }\end{array}$ \\
\hline & & & & \\
\hline
\end{tabular}

25. Para exercer cargos de gestão intermédia (coordenação) deveria ser obrigatório ter formação pós-graduada em gestão

\begin{tabular}{|c|c|c|c|c|}
\hline $\begin{array}{c}\text { Discordo } \\
\text { totalmente }\end{array}$ & $\begin{array}{c}\text { Discordo } \\
\text { parcialmente }\end{array}$ & $\begin{array}{c}\text { Não } \\
\text { concordo } \\
\text { nem discordo }\end{array}$ & $\begin{array}{c}\text { Concordo } \\
\text { parcialmente }\end{array}$ & $\begin{array}{c}\text { Concordo } \\
\text { totalmente }\end{array}$ \\
\hline & & & & \\
\hline
\end{tabular}

26. Os PTS estão preparados para participar na orientação e gestão de serviços lado a lado com outros profissionais

\begin{tabular}{|c|c|c|c|c|}
\hline $\begin{array}{c}\text { Discordo } \\
\text { totalmente }\end{array}$ & $\begin{array}{c}\text { Discordo } \\
\text { parcialmente }\end{array}$ & $\begin{array}{c}\text { Não } \\
\text { concordo } \\
\text { nem discordo }\end{array}$ & $\begin{array}{c}\text { Concordo } \\
\text { parcialmente }\end{array}$ & $\begin{array}{c}\text { Concordo } \\
\text { totalmente }\end{array}$ \\
\hline & & & & \\
\hline
\end{tabular}

27. As diferentes e diversas profissões das TS devem ser encaradas pela Gestão como integrantes de uma rede de cuidados de saúde

\begin{tabular}{|c|c|c|c|c|}
\hline $\begin{array}{c}\text { Discordo } \\
\text { totalmente }\end{array}$ & $\begin{array}{c}\text { Discordo } \\
\text { parcialmente }\end{array}$ & $\begin{array}{c}\text { Não } \\
\text { concordo } \\
\text { nem discordo }\end{array}$ & $\begin{array}{c}\text { Concordo } \\
\text { parcialmente }\end{array}$ & $\begin{array}{c}\text { Concordo } \\
\text { totalmente }\end{array}$ \\
\hline & & & & \\
\hline
\end{tabular}


28. As diferentes e diversas profissões das TS realizam contribuições complementares na criação de valor para o cliente

\begin{tabular}{|c|c|c|c|c|}
\hline $\begin{array}{c}\text { Discordo } \\
\text { totalmente }\end{array}$ & $\begin{array}{c}\text { Discordo } \\
\text { parcialmente }\end{array}$ & $\begin{array}{c}\text { Não } \\
\text { concordo } \\
\text { nem discordo }\end{array}$ & $\begin{array}{c}\text { Concordo } \\
\text { parcialmente }\end{array}$ & $\begin{array}{c}\text { Concordo } \\
\text { totalmente }\end{array}$ \\
\hline & & & & \\
\hline
\end{tabular}

29. A integração em rede implica tratamento como par e igual, no respeito pelo saber próprio de cada profissional e pelo seu contributo para a eficácia global do cuidado de saúde

\begin{tabular}{|c|c|c|c|c|}
\hline $\begin{array}{c}\text { Discordo } \\
\text { totalmente }\end{array}$ & $\begin{array}{c}\text { Discordo } \\
\text { parcialmente }\end{array}$ & $\begin{array}{c}\text { Não } \\
\text { concordo } \\
\text { nem discordo }\end{array}$ & $\begin{array}{c}\text { Concordo } \\
\text { parcialmente }\end{array}$ & $\begin{array}{c}\text { Concordo } \\
\text { totalmente }\end{array}$ \\
\hline & & & & \\
\hline
\end{tabular}

30. Entendo o processo do cuidado em saúde como um puzzle com peças diferentes mas perfeitamente ajustáveis e não como fragmentado

\begin{tabular}{|c|c|c|c|c|}
\hline $\begin{array}{c}\text { Discordo } \\
\text { totalmente }\end{array}$ & $\begin{array}{c}\text { Discordo } \\
\text { parcialmente }\end{array}$ & $\begin{array}{c}\text { Não } \\
\text { concordo } \\
\text { nem discordo }\end{array}$ & $\begin{array}{c}\text { Concordo } \\
\text { parcialmente }\end{array}$ & $\begin{array}{c}\text { Concordo } \\
\text { totalmente }\end{array}$ \\
\hline & & & & \\
\hline
\end{tabular}

31. Com as direções de serviço enraizadas nas suas «quintas e quintinhas» duvido que o paradigma de gestão venha a ser alterado algum dia

\begin{tabular}{|c|c|c|c|c|}
\hline $\begin{array}{c}\text { Discordo } \\
\text { totalmente }\end{array}$ & $\begin{array}{c}\text { Discordo } \\
\text { parcialmente }\end{array}$ & $\begin{array}{c}\text { Não } \\
\text { concordo } \\
\text { nem discordo }\end{array}$ & $\begin{array}{c}\text { Concordo } \\
\text { parcialmente }\end{array}$ & $\begin{array}{c}\text { Concordo } \\
\text { totalmente }\end{array}$ \\
\hline & & & & \\
\hline
\end{tabular}

32. Na organização onde exerço há PTS a exercer cargos de gestão

\begin{tabular}{|l|l|l|}
\hline Coordenação & Sim $\rceil$ & Não $\mid$ \\
\hline Técnico Director & Sim $\rceil$ & Não $\mid$ \\
\hline
\end{tabular}

33. Está constituído o Conselho das Tecnologias da Saúde (TS) Sim ; Não
34. O Conselho das TS funciona
Sim ; Não

35. Será quase inevitável a diluição de algumas profissões das TS noutras quando a formação for idêntica

\begin{tabular}{|c|c|c|c|c|}
\hline $\begin{array}{c}\text { Discordo } \\
\text { totalmente }\end{array}$ & $\begin{array}{c}\text { Discordo } \\
\text { parcialmente }\end{array}$ & $\begin{array}{c}\text { Não } \\
\text { concordo } \\
\text { nem discordo }\end{array}$ & $\begin{array}{c}\text { Concordo } \\
\text { parcialmente }\end{array}$ & $\begin{array}{c}\text { Concordo } \\
\text { totalmente }\end{array}$ \\
\hline & & & & \\
\hline
\end{tabular}

36. Os cursos das TS não devem perder a sua individualidade porque cada um se funda em saberes específicos

\begin{tabular}{|c|c|c|c|c|}
\hline $\begin{array}{c}\text { Discordo } \\
\text { totalmente }\end{array}$ & $\begin{array}{c}\text { Discordo } \\
\text { parcialmente }\end{array}$ & $\begin{array}{c}\text { Não } \\
\text { concordo } \\
\text { nem discordo }\end{array}$ & $\begin{array}{c}\text { Concordo } \\
\text { parcialmente }\end{array}$ & $\begin{array}{c}\text { Concordo } \\
\text { totalmente }\end{array}$ \\
\hline & & & & \\
\hline
\end{tabular}

37. As competências e capacitação dos PTS são essenciais e perfeitamente adequadas às necessidades em saúde das Pessoas

\begin{tabular}{|c|c|c|c|c|}
\hline $\begin{array}{c}\text { Discordo } \\
\text { totalmente }\end{array}$ & $\begin{array}{c}\text { Discordo } \\
\text { parcialmente }\end{array}$ & $\begin{array}{c}\text { Não } \\
\text { concordo }\end{array}$ & $\begin{array}{c}\text { Concordo } \\
\text { parcialmente }\end{array}$ & $\begin{array}{c}\text { Concordo } \\
\text { totalmente }\end{array}$ \\
\hline
\end{tabular}




\begin{tabular}{|l|l|l|l|l|}
\hline & & nem discordo & & \\
\hline & & & & \\
\hline
\end{tabular}

38. O que no futuro virá a pesar é a forma como cada profissão for capaz de consolidar a sua identidade

\begin{tabular}{|c|c|c|c|c|}
\hline $\begin{array}{c}\text { Discordo } \\
\text { totalmente }\end{array}$ & $\begin{array}{c}\text { Discordo } \\
\text { parcialmente }\end{array}$ & $\begin{array}{c}\text { Não } \\
\text { concordo } \\
\text { nem discordo }\end{array}$ & $\begin{array}{c}\text { Concordo } \\
\text { parcialmente }\end{array}$ & $\begin{array}{c}\text { Concordo } \\
\text { totalmente }\end{array}$ \\
\hline & & & & \\
\hline
\end{tabular}

39. Faz todo o sentido trabalhar as profissões em clusters (agrupamentos) estruturados por ciências fundamentais

\begin{tabular}{|c|c|c|c|c|}
\hline $\begin{array}{c}\text { Discordo } \\
\text { totalmente }\end{array}$ & $\begin{array}{c}\text { Discordo } \\
\text { parcialmente }\end{array}$ & $\begin{array}{c}\text { Não } \\
\text { concordo } \\
\text { nem discordo }\end{array}$ & $\begin{array}{c}\text { Concordo } \\
\text { parcialmente }\end{array}$ & $\begin{array}{c}\text { Concordo } \\
\text { totalmente }\end{array}$ \\
\hline & & & & \\
\hline
\end{tabular}

40. A formação pode consistir num "tronco comum", seguido de especialização

\begin{tabular}{|c|c|c|c|c|}
\hline $\begin{array}{c}\text { Discordo } \\
\text { totalmente }\end{array}$ & $\begin{array}{c}\text { Discordo } \\
\text { parcialmente }\end{array}$ & $\begin{array}{c}\text { Não } \\
\text { concordo } \\
\text { nem discordo }\end{array}$ & $\begin{array}{c}\text { Concordo } \\
\text { parcialmente }\end{array}$ & $\begin{array}{c}\text { Concordo } \\
\text { totalmente }\end{array}$ \\
\hline & & & & \\
\hline
\end{tabular}

41. As profissões das TS devem continuar a organizar-se como um só grupo

\begin{tabular}{|c|c|c|c|c|}
\hline $\begin{array}{c}\text { Discordo } \\
\text { totalmente }\end{array}$ & $\begin{array}{c}\text { Discordo } \\
\text { parcialmente }\end{array}$ & $\begin{array}{c}\text { Não } \\
\text { concordo } \\
\text { nem discordo }\end{array}$ & $\begin{array}{c}\text { Concordo } \\
\text { parcialmente }\end{array}$ & $\begin{array}{c}\text { Concordo } \\
\text { totalmente }\end{array}$ \\
\hline & & & & \\
\hline
\end{tabular}

42. Os PTS detêm competências adequadas para fazer face aos desafios que se colocam na área da saúde, nomeadamente uma orientação cada vez maior para a educação para a saúde e sua promoção e para a prevenção da doença, junto das comunidades

\begin{tabular}{|c|c|c|c|c|}
\hline $\begin{array}{c}\text { Discordo } \\
\text { totalmente }\end{array}$ & $\begin{array}{c}\text { Discordo } \\
\text { parcialmente }\end{array}$ & $\begin{array}{c}\text { Não } \\
\text { concordo } \\
\text { nem discordo }\end{array}$ & $\begin{array}{c}\text { Concordo } \\
\text { parcialmente }\end{array}$ & $\begin{array}{c}\text { Concordo } \\
\text { totalmente }\end{array}$ \\
\hline & & & & Sim \\
\hline
\end{tabular}
$\begin{aligned} & \text { 43. Pertence a alguma Associação Profissional/ Sindical? } \\
& \text { Já alguma vez pensou em mudar de profissão? }\end{aligned}$
qual? Sim Não

44. Qual a sua idade? Anos

45. Sexo: Feminino $\square$;Masculino

46. PROFISSÃO:

47. ÁREA DE ATIVIDADE:

48. ANOS DE ATIVIDADE PROFISSIONAL Anos

49. CURSO

50. ANO EM QUE CONCLUIU O CURSO (BACHARELATO)

51. ANO EM QUE CONCLUIU A LICENCIATURA

52. ESCOLA ONDE CONCLUIU O CURSO 
53. HABILITAÇÕES

\begin{tabular}{|c|c|}
\hline$<12^{\circ}$ Ano & \\
\hline $12^{\circ}$ Ano & \\
\hline Bacharelato & \\
\hline Licenciatura & \\
\hline
\end{tabular}

54. TEM ALGUMA PÓS-GRADUAÇÃO, ESPECIALIZAÇÃO OU GRAU SUPERIOR?

55. Se sim, qual?

$\operatorname{Sim} \square$; Não

56. Em que ano concluiu?

57. Em que instituição de ensino?

58. TEM MAIS QUE UM LOCAL DE TRABALHO?

$\operatorname{Sim} \square$;Não $\square$

Nota - Se sim, assinale as várias opções nas respostas às perguntas 60, 61 e 62 .

59. INSTITUIÇÃO/ÕES EM QUE EXERCE:

60. NATUREZA JURÍdiCA DA INSTITUIÇÃO

\begin{tabular}{|l|c|}
\hline Hospital público & \rceil \\
\hline Hospital EPE & \rceil \\
\hline Parceria Público/ Privado & \rceil \\
\hline Unidade Local de Saúde & \rceil \\
\hline ACES & \rceil \\
\hline USF & \rceil \\
\hline Centro de Saúde & \rceil \\
\hline Escola & \rceil \\
\hline Empresa Privada & \rceil \\
\hline Organismo Público & \rceil \\
\hline Por conta própria & \rceil \\
\hline
\end{tabular}

61. QUAL O REGIME QUE O LIGA À ATUAL INSTITUIÇÃO?

\begin{tabular}{|l|c|}
\hline Sou do "quadro" da função pública & $\uparrow$ \\
\hline Sou do Contrato Individual de Trabalho & $\uparrow$ \\
\hline Trabalho mediante Recibo verde & \rceil \\
\hline Estou em Contrato a termo incerto & \rceil \\
\hline Tenho um Contrato a termo certo, por__meses & \rceil \\
\hline
\end{tabular}

Fim do questionário. Muito obrigada pela sua colaboração. 